\title{
An Eight Element Dual Band Antenna for Future 5G Smartphones
}

\author{
Haider Ali ${ }^{1, *(\mathbb{D},}$, Xin-Cheng Ren ${ }^{2, *}$, Anas M. Hashmi ${ }^{3}{ }^{(}$, Muhammad Rizwan Anjum $^{4}$, Inam Bari ${ }^{5}(\mathbb{D}$, \\ Saad Ijaz Majid ${ }^{1,6}$, Naveed Jan ${ }^{1}$, Wajahat Ullah Khan Tareen ${ }^{3}$, Amjad Iqbal ${ }^{7}$ (D) and Muhammad Abbas Khan ${ }^{8}$ \\ 1 Department of Electrical and Electronics Engineering Technology, University of Technology, \\ Nowshera 24100, Pakistan; saad@uotnowshera.edu.pk (S.I.M.); naveed.jan@uotnowshera.edu.pk (N.J.) \\ 2 School of Physics and Electronic Information, Yanan University, Yan'an 761000, China \\ 3 Department of Electrical and Electronic Engineering, College of Engineering, University of Jeddah, \\ Jeddah 21589, Saudi Arabia; ahashmi@uj.edu.sa (A.M.H.); wtareen@uj.edu.sa (W.U.K.T.) \\ 4 Department of Electronic Engineering, The Islamia University of Bahawalpur, Bahawalpur 63100, Pakistan; \\ engr.muhammadrizwan@gmail.com \\ 5 Systems Engineering Department, Military Technological College, Muscat 111, Oman; inam.bari@mtc.edu.om \\ 6 Department of Electrical Engineering, University of Engineering and Technology, Peshawar 25000, Pakistan \\ 7 Centre for Wireless Technology (CWT), Faculty of Engineering, Multimedia University, \\ Melaka 75450, Malaysia; amjad730@gmail.com \\ 8 Department of Electrical Engineering, Balochistan University of Information Technology Engineering and \\ Management Sciences, Quetta 87300, Pakistan; Muhammad.abbas@buitms.edu.pk \\ * Correspondence: haider.ali@uotnowshera.edu.pk (H.A.); xchren@yau.edu.cn (X.-C.R.)
}

check for updates

Citation: Ali, H.; Ren, X.-C.; Hashmi, A.M.; Anjum, M.R.; Bari, I.; Majid, S.I.; Jan, N.; Tareen, W.U.K.; Iqbal, A.; Khan, M.A. An Eight Element Dual Band Antenna for Future 5G Smartphones. Electronics 2021, 10, 3022. https://doi.org/10.3390/ electronics10233022

Academic Editor: Alejandro Melcón Alvarez

Received: 12 November 2021

Accepted: 1 December 2021

Published: 3 December 2021

Publisher's Note: MDPI stays neutral with regard to jurisdictional claims in published maps and institutional affiliations.

Copyright: (c) 2021 by the authors. Licensee MDPI, Basel, Switzerland. This article is an open access article distributed under the terms and conditions of the Creative Commons Attribution (CC BY) license (https:/ / creativecommons.org/licenses/by/ $4.0 /)$.
Abstract: The demand of $5 \mathrm{G}$ in modern communication era due to its high data rate, reliable connectivity and low latency is enormous. This paper presents a novel dual band antenna resonating at two distinct bands allotted for $5 \mathrm{G}$ services. The proposed antenna is composed of inverted $\mathrm{L}$ shape probes comprising a rectangular defected ground structure. The propose antenna covers $3.4-3.6 \mathrm{GHz}$ and 5.4-5.6 GHz spectrum. In propose MIMO system, the efficiency ranges from 52 to $69 \%$ with peak gain of $3.1 \mathrm{dBi}$. The proposed antenna system is sufficiently isolated with minimum value of $13 \mathrm{~dB}$ and ECC less than 0.05 among any two radiating elements. Similarly, the channel capacity is found to be 38 and 39.5 at both resonating bands at $20 \mathrm{~dB}$ SNR and diversity and mean effective gains lies in acceptable range. The radiation characteristics of the proposed design shows that the proposed antenna is providing good diversity characteristics and SAR values have demonstrated to be safe for user vicinity. The proposed dual band antenna prototype is developed tested. With the measured results obtained, the MIMO system proposed can be seen as vital candidate for 5G LTE band 42 and 46 services.

Keywords: 5G; MIMO terminals; ECC; SAR; handheld devices

\section{Introduction}

With the steady evolvement of 5G technology, the 5G infrastructure has been deployed on industrial scale throughout the communication world. The 5th generation networks are better than its predecessors in terms of connectivity, low latency, high data rate and stability [1-3]. In order to deploy the 5G technology in the mobile phones, a six element Multiple Input Multiple Output (MIMO) or greater number of radiating elements are needed. In literature, several studies have been conducted with number of radiating elements ranging from six up to 18 elements [4-8]. These antennas presented have been form of either in planar or mounted on side edges of the board. The higher number of radiating elements usually gives upper edge in ergodic channel capacity but the isolation issues arises.

A six element MIMO in [4] offers peak gain of $3.1 \mathrm{dBi}$ with minimum isolation of $-10 \mathrm{~dB}$. The size of substrate used (FR4) in the study was $136 \times 68 \mathrm{~mm}^{2}$ and the 
slot antenna size varied up to $3 \times 8 \mathrm{~mm}^{2}$ generating $200 \mathrm{MHz}$ bandwidth with central frequency of $3.5 \mathrm{GHz}$. Similarly, in [5] a MIMO array of eight resonators having the overall size of $4.6 \times 5.6$ for radiating element is presented, with $400 \mathrm{MHz}$ bandwidth ranging from $3.3 \mathrm{GHz}$ to $3.7 \mathrm{GHz}$. In [6], a MIMO antenna system is offered in which the radiating elements have been increased up to 18. The minimum isolation in this proposed study is $16 \mathrm{~dB}$ with peak calculated channel capacity of $81 \mathrm{Bps} / \mathrm{Hz}$ and bandwidth ranging from 3.3 GHz to 3.8 GHz covering LTE band 43.

Although LTE band 42 and band 43 are licensed for 5G spectrum, they cannot satisfy and fulfill the demand for higher data rate required for $5 \mathrm{G}$ services. LTE band 46 $(5.1$ to $5.9 \mathrm{GHz}$ ) has great potential in order to fulfill the $5 \mathrm{G}$ requirements. Several antenna systems have been proposed in order to cover both LTE band 42, 43 and 46 in literature [9-15]. A dual band antenna system is presented in [9], resonating at two distinct 5G allotted bands of 3.5 and $5.5 \mathrm{GHz}$. The second resonance is generated with the ground slot as the first resonance operates the fundamental quarter wavelength mode giving isolation of 10dB. Covering LTE band 42 and 46, an 8 element MIMO array is presented in [10]. The desired bandwidths are achieved using two radiators namely monopole and slot antenna with ECC less than 0.2 and peak channel capacity of $40 \mathrm{bps} / \mathrm{Hz}$. Yet, the hybrid arrangement makes the array a bit complex and expose to fabricating errors. An interesting study in [11] shows the MIMO system of $\pi$ and L shape radiators. The resonance response of the reported study was tri band and ECC was seen well below 0.2.

A hybrid antenna system resonating at LTE band 41 and Band 42 covering 2.6 to 3.6 GHz is presented in [12]. The proposed Hybrid antenna system is assembled by four antenna radiators place horizontally at the corner of the chassis and the remaining four are mounted vertically at the central sides. The ECC of among any two radiating elements is less than 0.2 with peak channel capacity of $38.5 \mathrm{bps} / \mathrm{Hz}$, but the complex geometry of the proposed hybrid system limits its use in practical applications. A folded eight element monopole system in [13] resonates at LTE band 41 and 42 with modified decoupling structure. Although the antenna is well designed but the folded monopole antennas with additional decoupling structures make other RF devices difficult to be integrated. An eight element dual band antenna resonating at one $4 \mathrm{G}$ and one 5G band is presented in [14]. The proposed MIMO system is designed in planar manner with four elements on each side. The middle antennas are bound with common ground slot and the overall size of the antenna is too much to employ other RF components.

This article presents a novel shape eight element MIMO antenna system resonating at two distinct bands of LTE band 42 and band 46. The proposed antenna system comprises of L shape inverted radiators with a ground induced rectangular slots. The proposed dual band antenna is etched on FR4 board commonly used for smart phones and the simulated results are validated through fabricated prototype measurements. The paper is organized as following.

Section 1 provides general introduction of the MIMO systems for $5 \mathrm{G}$. Section 2 covers the proposed antenna design process. Section 3 covers the results and discussions on fabricated prototype of the proposed MIMO antenna and other key performance parameters. Furthermore, a comparison table of the proposed MIMO system with state of the art published literature is also included. In last conclusion is given.

\section{Antenna Design}

The presented dual band antenna is made on FR4 board with relative thickness of $1.6 \mathrm{~mm}$ and having permittivity of 4.4 with loss tangent 0.02 . The board size is kept $150 \times 75 \mathrm{~mm}^{2}$. The size of the board is adjusted by keeping the standard size of modern smart phones. The proposed dual band antenna overall layout can be seen at Figure 1. The radiating elements of MIMO system are arranged in symmetrical manner and both sides of the board contain four elements. The radiating element is composed of inverted modified L shape strip. The transmission line length is $11 \mathrm{~m}$ with width of $2.5 \mathrm{~mm}$. The length of the antenna feed line is adjusted to ensure maximum power transfer through 
radiating elements. Each radiating element contains a rectangular ground slot. This slot helps in lower resonance mode and is crucial in antenna design aspect. The dimensions of the proposed antenna are: $\mathrm{rx}=1, \mathrm{ry}=2, \mathrm{Fx}=3, \mathrm{Fy}=4, \mathrm{gsx}=5$, gsy $=6 \mathrm{~mm}$. A ground clearance of $5 \times 75 \mathrm{~mm}^{2}$ is kept on both top and bottom side of ground plane. For feeding co axial probes are designed. In the proposed MIMO system as well as other published literature, the same feeding techniques have been applied. The propose MIMO system can be implemented with microstrip line techniques or discrete ports while manufacturing on industrial scale.

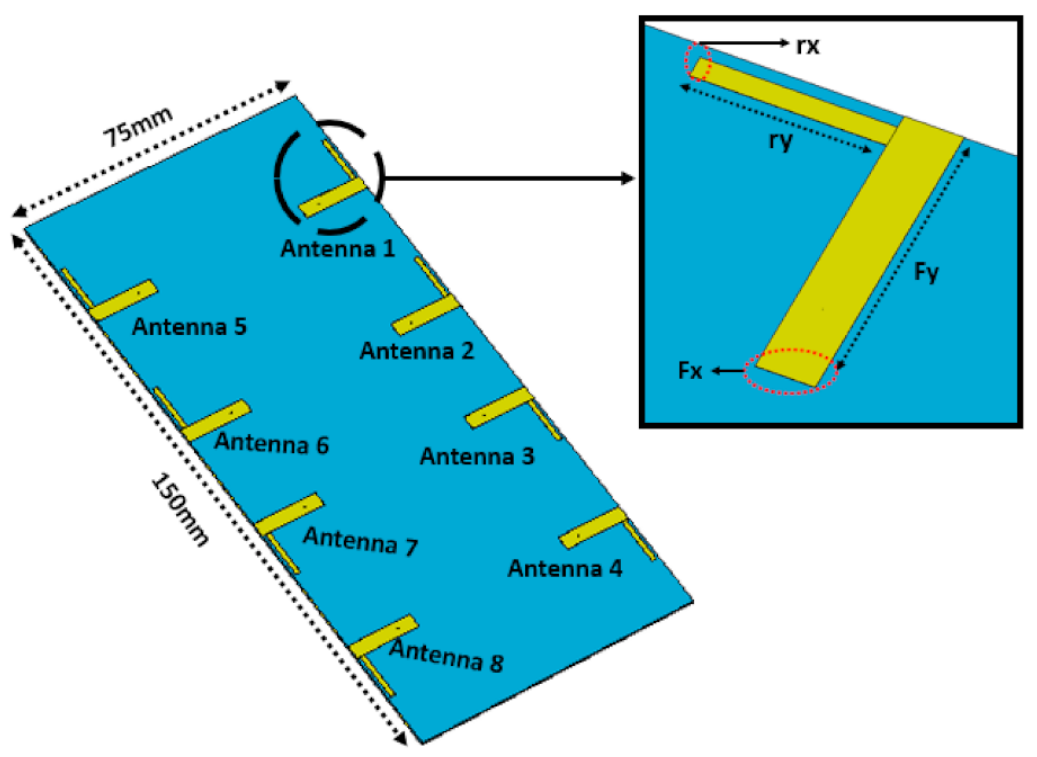

(a)

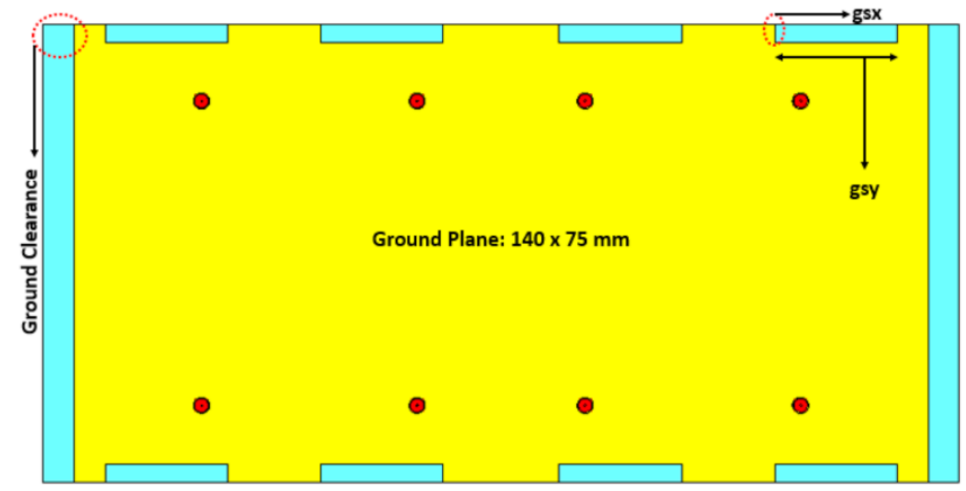

(b)

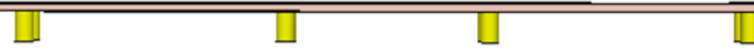

(c)

Figure 1. Proposed Dual Band Antenna View. (a) Overall Front View with close view of single element (b) Back View (c) Bottom View showing coaxial connections.

The surface currents of the proposed antenna at resonating frequencies of $3.5 \mathrm{GHz}$ and $5.5 \mathrm{GHz}$ are shown in Figure 2. From Figure 2, it can be seen that both resonance modes are generated alongside the edges of the inverted shape L probe and the DGS. Induced at the ground plane. 


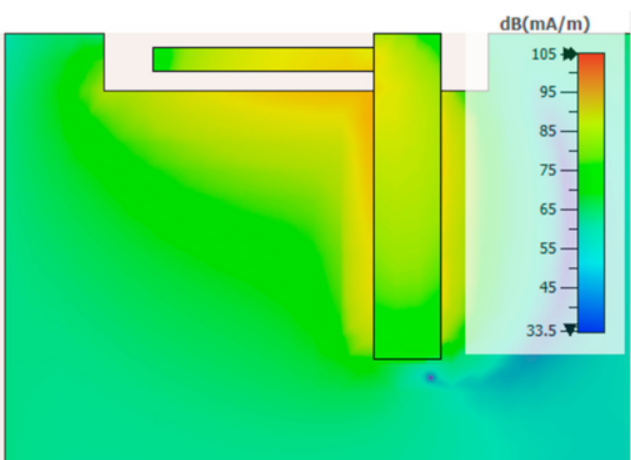

(a)

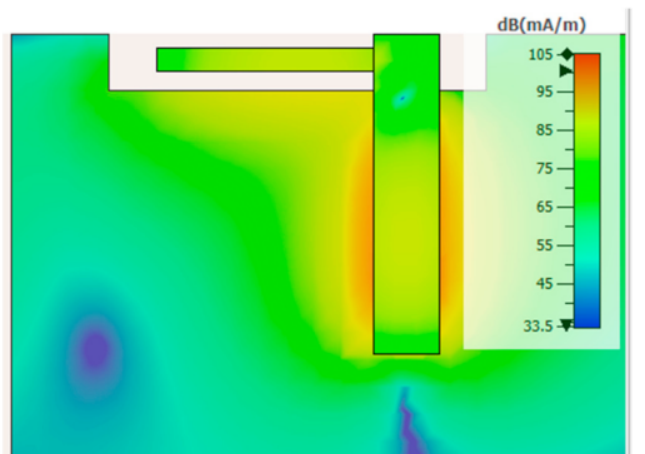

(b)

Figure 2. Surface Current Patterns. (a) $3.5 \mathrm{GHz}$ (b) $5.5 \mathrm{GHz}$.

Figure 3 shows the s-parameter response of the proposed MIMO antenna system. Due to symmetry of the board, the one side of the MIMO has been selected only to discuss the S-parameters. As from Figure 3a, MIMO system is seen resonating at two distinct bands allocated for $5 \mathrm{G}$ services with central resonances of 3.5 and $5.5 \mathrm{GHz}$. The minimum isolation obtained at the proposed MIMO antenna system is $12 \mathrm{~dB}$ at central resonance of 3.5 GHz while at $5.5 \mathrm{GHz}$ resonance the isolation is seen as less than $20 \mathrm{~dB}$.

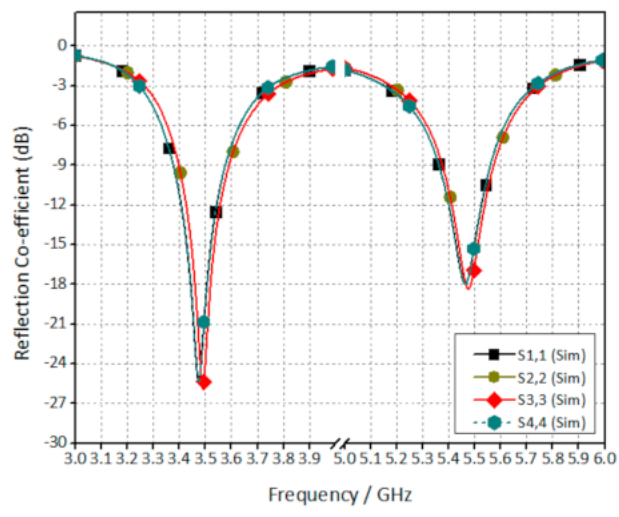

(a)

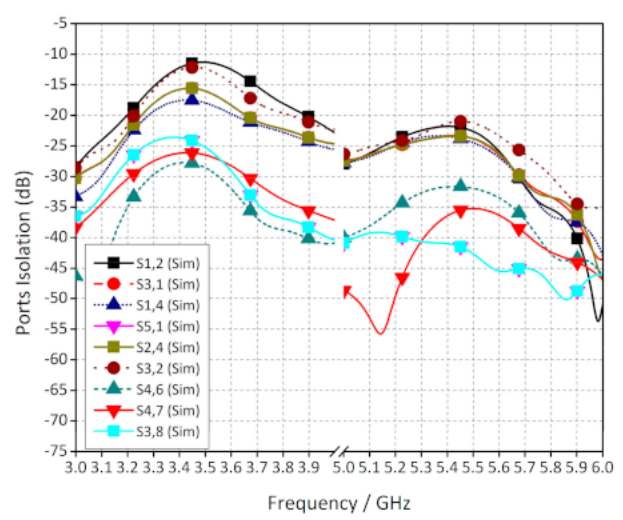

(b)

Figure 3. Simulated S-Parameters of Ant1 Ant2 Ant3 Ant4. (a) Reflection Coefficient (b) Ports Isolation.

The proposed antenna dual band response has been attained by series of steps including different parametrical studies of the resonating antennas. In Figure 4 three parameters are discussed to describe the role of different strips and slots in generation of dual band response. In Figure 4a, the parameter ry is analyzed from $9.5 \mathrm{~mm}$ to $13.5 \mathrm{~mm}$ value with intervals of $1 \mathrm{~mm}$. It was observed that with that lower values, the response of the dual band antenna approached to single band nearly and the higher band response was nearly diminished with lower band response shifted forward from desired band to $3.9 \mathrm{GHz}$. Furthermore, with step by step 1mm interval increase it was observed that the higher order generated dual band response and the desired response was attained at the optimum value of $11.5 \mathrm{~mm}$. 


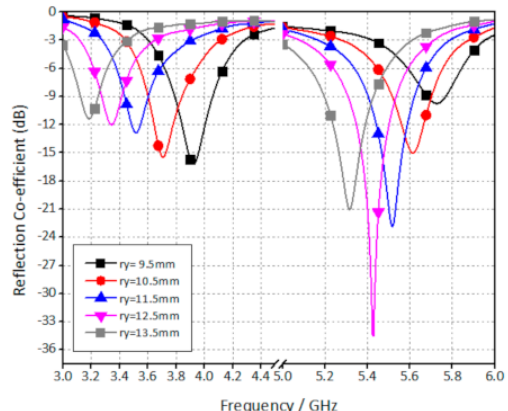

(a)

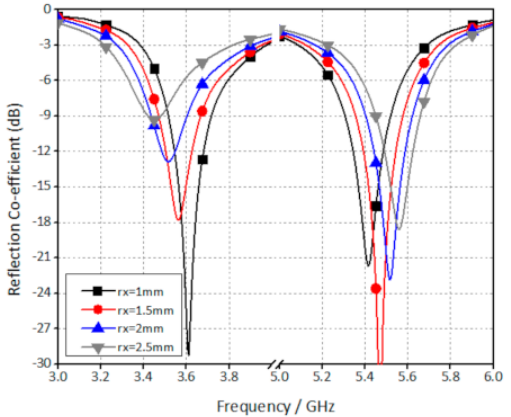

(b)

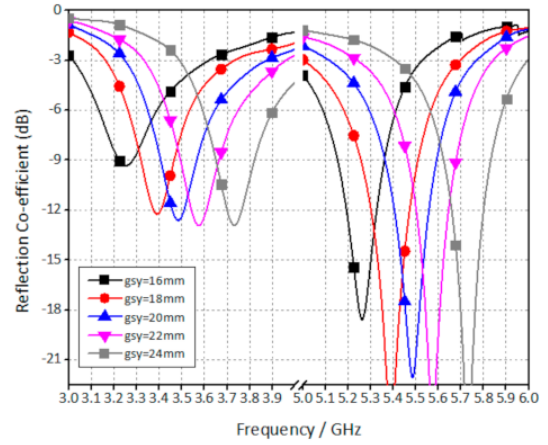

(c)

Figure 4. Parametric Analysis of proposed eight port MIMO system. (a) ry (b) rx (c) gsy.

At this value, both the desired frequencies were achieved and the response of the system with further increase resulted in single resonance again but as opposite of the first parametrical response i.e., the lower resonance started diminishing. Figure $4 \mathrm{~b}$ shows the parametrical response of the parameter rx. The parametrical response was observed at the interval of $0.5 \mathrm{~mm}$. The rx value was set from $1 \mathrm{~mm}$ to $2.5 \mathrm{~mm}$. The role of the rx after the parametric sweep was seen as less effective as compared to length parameter ry. The optimum value was attained at $2 \mathrm{~mm}$. In Figure $4 \mathrm{c}$ the role of ground slot was investigated. The parametric value was set to be from $16 \mathrm{~mm}$ to $24 \mathrm{~mm}$ with regular intervals of $2 \mathrm{~mm}$. Since the overall length of the ground is big therefore the value of the paramedic interval was kept at $2 \mathrm{~mm}$ to obtained reasonable response. It was observed that the length of the ground slot plays an important role in generating the dual band response and with every $2 \mathrm{~mm}$ increase in length resulted in shifting the resonance frequency forward. The desired frequency response was achieved at $20 \mathrm{~mm}$ length. The parametric analysis approach has been a common method used in novel devices modelling throughout literature [15-18].

\section{Results and Discussions}

In order to verify results, obtain from simulations, the proposed dual band antenna system is fabricated and is tested at in house facility. The proposed fabricated prototype is shown in Figure 5. The prototype is fabricated using LPFK machine.

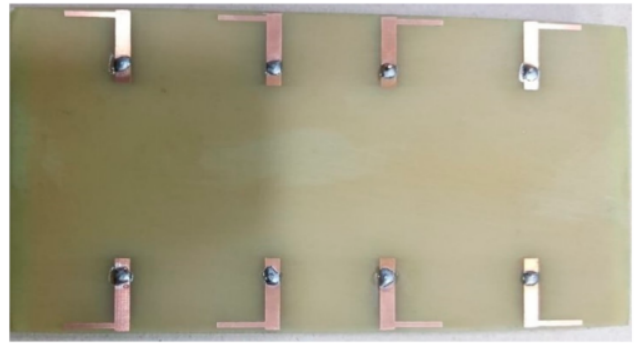

(a)

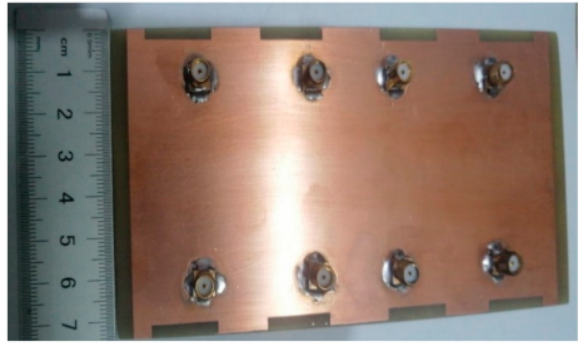

(b)

Figure 5. Proposed Dual band antenna fabricated prototype. (a) Front (b) Back. 


\subsection{S-Parameters}

The measured reflection coefficients and ports isolation are shown in Figure 6. Through the measurements it can easily be seen that fabricated prototype measured results are in close agreement with simulations. The small shift in the results can be attributed to the measurement set up, fabrication small errors and cable losses. As in Figure 6, the reflection co-efficient of antenna shows that the resonation at both the desired resonances is well achieved, the minimum measured isolation is found to be $14 \mathrm{~dB}$ which is $2 \mathrm{~dB}$ lower than the simulated results.

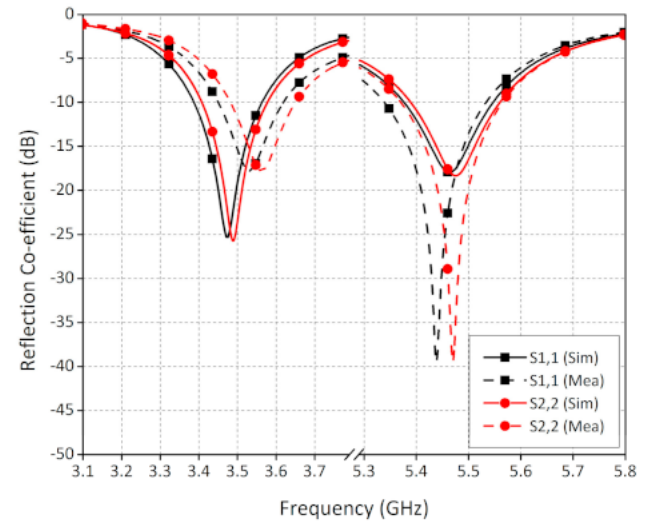

(a)

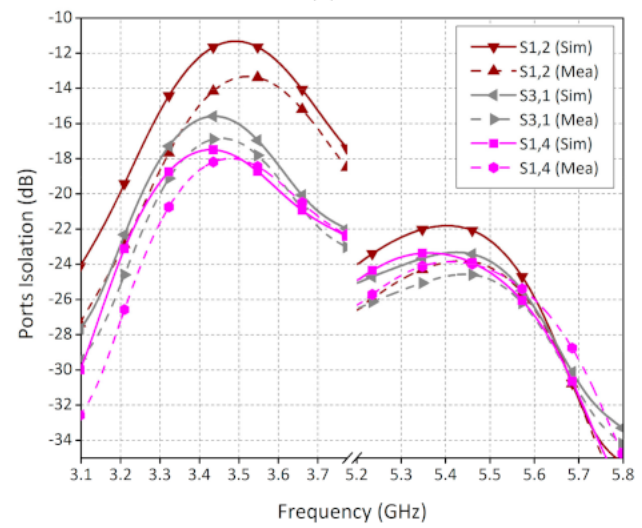

(c)

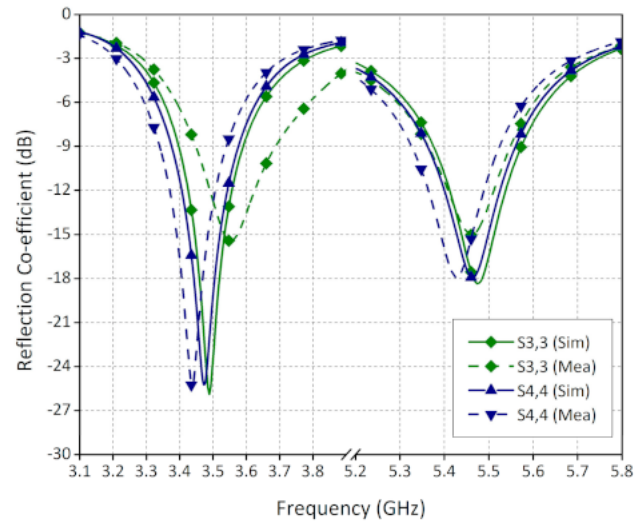

(b)

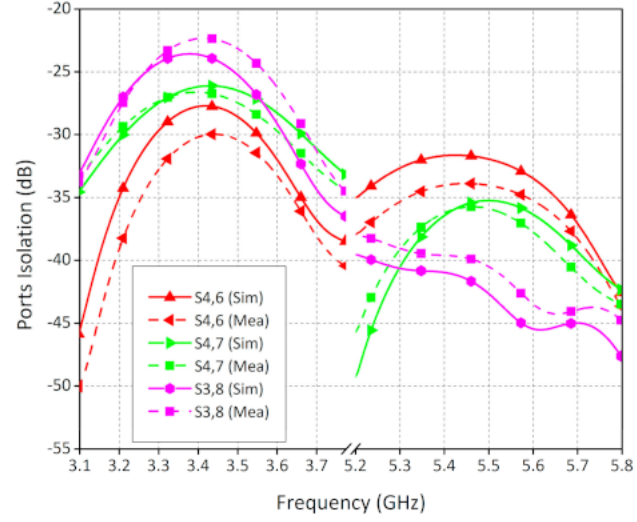

(d)

Figure 6. Measured S-Parameters of Ant1 Ant2 Ant3 Ant4. (a) Reflection Coefficient Ant 1 and Ant 2 (b) Reflection Coefficient Ant 3 and Ant 4 (c) Selected Ports Isolation Ant 1 (d) Selected Ports Isolation Ant 4 Ant 3.

\subsection{Radiation Patterns}

The proposed dual band MIMO antenna radiation patterns are presented in Figure 7 covering two principle planes of Phi 90 and Theta 90. The purpose of MIMO antenna system is to provide pattern and spatial diversity characteristics so that the reliability of signal reception is increased [19-23].

Figure 7a,b shows $\theta=90$ plane for Ant 1- Ant 4 and Figure 7c,d shows $\Phi=90$ plane for Ant 1-Ant 4. At $\theta=90$ plane the main lobe of the Ant 1 is focused on 30 degrees while Ant 3 is at opposite 330 degree Similarly Ant 2 main lobe magnitude is focused in between 0 to 30 while Ant 4 is opposite at that of Ant 2. Similarly, in Phi 90 plane, the direction of Ant 1 and Ant 2 is at 270 degrees while Ant 3 and Ant 4 is opposite of it hence providing better pattern diversity characteristics. The radiation patterns are in close proximity to each other. 


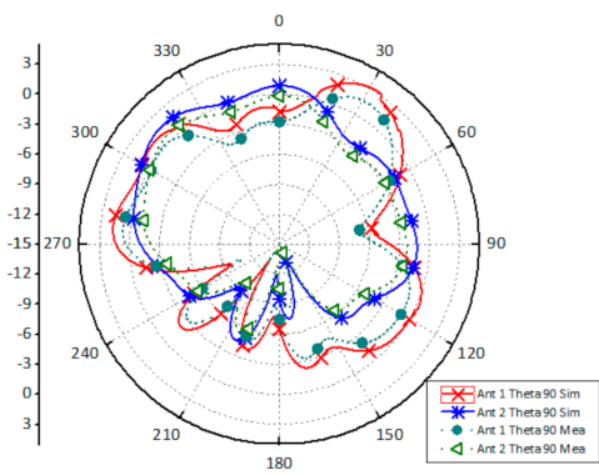

(a)

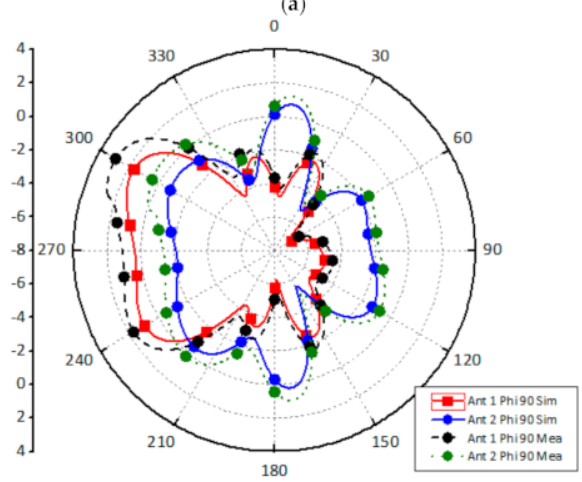

(c)

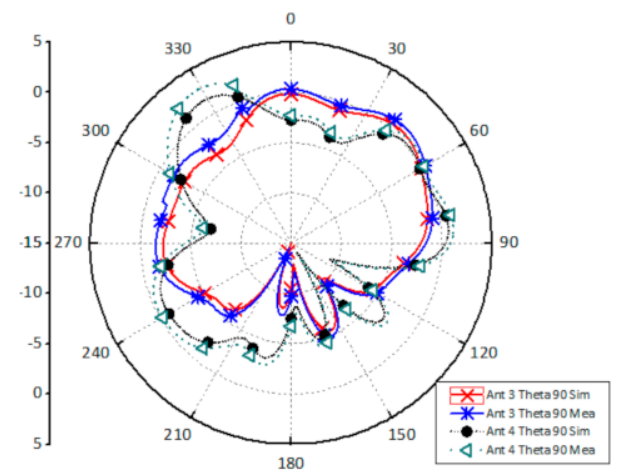

(b)

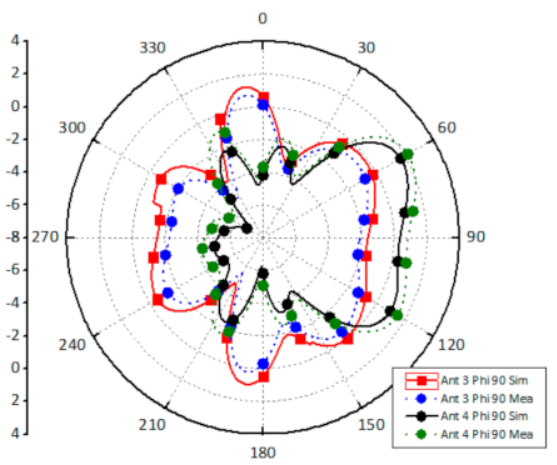

(d)

Figure 7. Radiation Patterns. (a) Ant 1 Ant 2 Theta 90 (b) Ant 3 Ant 4 Theta 90 (c) Ant 1 Ant 2 Phi 90 (d) Ant 3 Ant 4 Phi 90.

\subsection{Performance Parameters}

The performance parameters of the proposed antenna are shown in Figure 8. The efficiency of the proposed dual band antenna varies from $52 \%$ to $69 \%$ and due to proximity of the structure. The antenna gains ranges in range of $2.5 \mathrm{~dB}$ to $2.8 \mathrm{~dB}$. The efficiency is well better at operating band and the measured and simulated results are at nearly same.

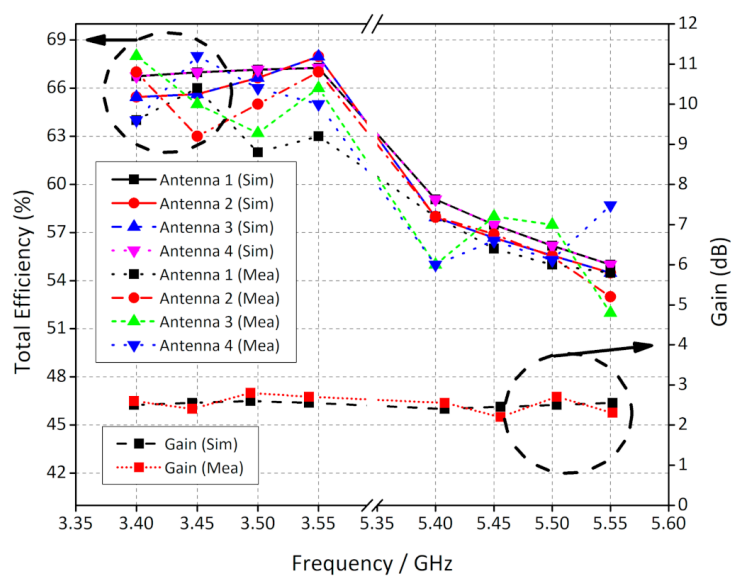

Figure 8. Performance parameters of proposed Dual band MIMO antenna.

\subsection{MIMO Performance Parameters}

The MIMIO performance parameters are necessary to evaluate the MIMO performances. Such parameters include Mean Effective Gain (MEGs), Envelope Correlation Coefficients (ECC), Diversity Gain (DG) and Channel Capacity (CC) Characteristics. The MIMO parameters are derived in literature [24-29]. Figure 9 shows the MIMO performance metrics. The ECC is measure of how well the radiating elements are isolated [30-33]. The 
ECC value obtained based on far field results is less than 0.7 throughout the operational bandwidth. The ECC and MEG are calculated using Equations (1) and (2).

$$
E C C=\frac{\left|\iint 4 \pi\left(\vec{B}_{i}(\theta, \varphi)\right) x\left(\vec{B}_{i}(\theta, \varphi)\right) d \Omega\right|^{2}}{\iint 4 \pi \mid\left(\left|\iint 4 \pi\left(\vec{B}_{i}(\theta, \varphi)\right)\right|^{2} d \Omega \iint 4 \pi\left|\left(\vec{B}_{i}(\theta, \varphi)\right)\right|_{2} d \Omega\right.}
$$

where $\vec{B}=(\theta, \Phi)$ denotes the 3D radiation pattern upon excitation of the $i$ th antenna and $\vec{B}=(\theta, \Phi)$ denotes the 3 D radiation pattern upon excitation of the $j$ th antenna. $\Omega$ is the solid angle.

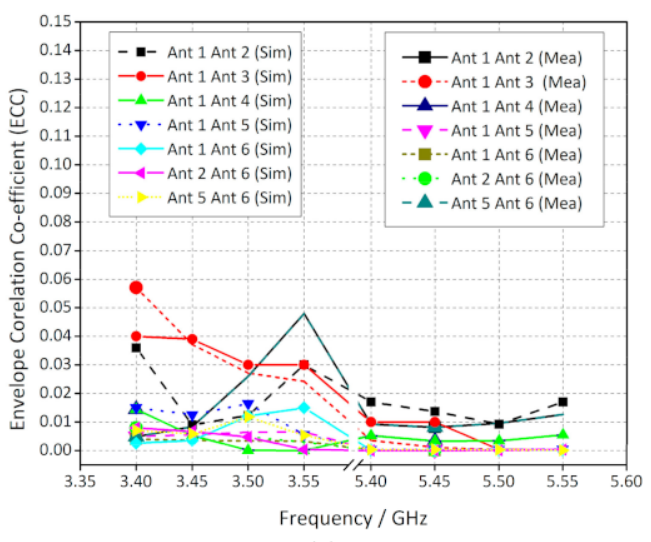

(a)

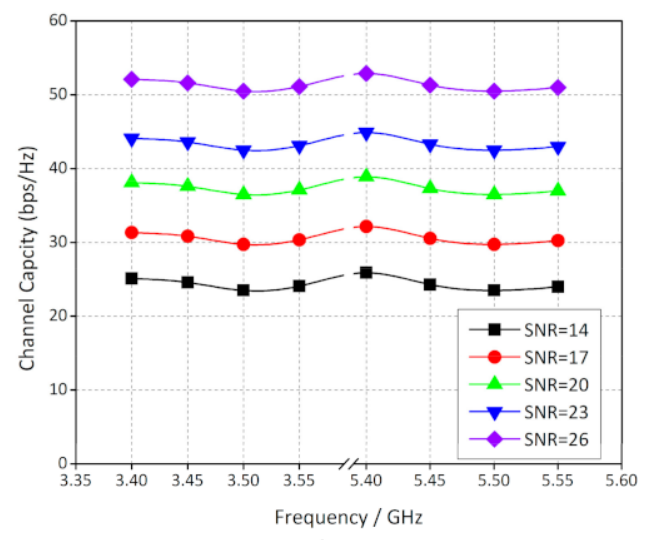

(b)

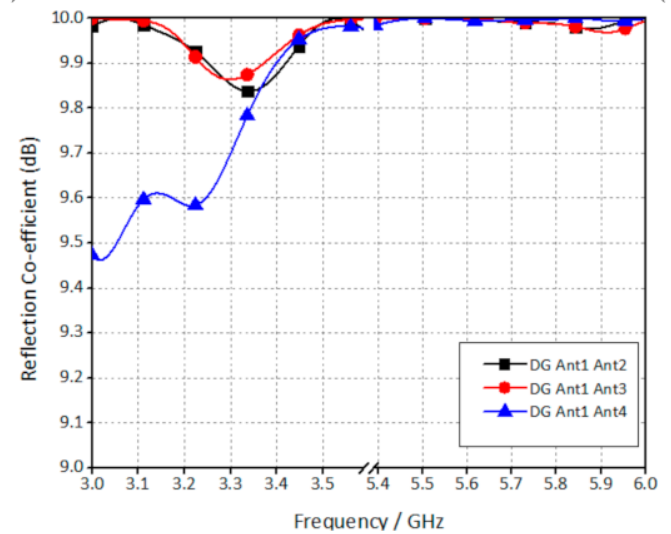

(c)

Figure 9. MIMO Parameters of proposed dual band Antenna. (a) ECC (b) Channel Capacity (c) Diversity Gain.

The Mean Effective Gain (MEG) of the proposed antenna system in order to satisfy the MIMO performance with good channel characteristics is mentioned in Table 1 . The MEGs are calculated using (2) based on the measured results of 2-D far field and meeting the requirement of $\mathrm{MEGi}=\mathrm{MEGj}$.

$$
M E G=\int_{-\pi}^{\pi} \int_{0}^{\pi} \frac{r}{r+1} G_{\varphi}(\theta, \varphi) P_{\varphi}(\theta, \varphi)+\frac{1}{1+r} G_{\varphi}(\theta, \varphi) \sin \theta d \theta d \varphi
$$


where $G_{\theta}=(\theta, \Phi)$ and $P_{\theta}=(\theta, \Phi)$ are angle of arrival and $r$ is the cross polar ratio which can be expressed as Equation (3).

$$
r=10 \log _{10} \frac{P_{v p a}}{P_{h p a}}
$$

where the power received by vertically polarized antenna and horizontally polarized antenna are represented as $P_{v p a}$ and $P_{h p a}$, respectively.

Table 1. Mean Effective Gain of proposed MIMO system.

\begin{tabular}{ccccccccc}
\hline Frequency (GHz) & MEG 1 & MEG 2 & MEG 3 & MEG 4 & MEG 5 & MEG 6 & MEG 7 & MEG 8 \\
\hline 3.5 & -3.10 & -3.51 & -3.33 & -3.41 & -2.99 & -3.89 & -4.1 & -2.79 \\
\hline 5.5 & -2.99 & -3.46 & -3.98 & -4.23 & -4.05 & -3.51 & -3.18 & -3.60 \\
\hline
\end{tabular}

The diversity gain is calculated using Equation (4).

$$
D G=10 \sqrt{1-(E C C)^{2}}
$$

As the communication technology progresses, channel resources distribution is an important phenomenon. In MIMO systems, as there are more radiating elements involved in both sender and receiver sides, hence the channel capacity in contrast with SISO system is much improved.

The channel capacity calculation of the proposed antenna is performed by assuming the transmitter side with full efficiency with considering Rayleigh Fading environment (channels to be identically distributed). The ergodic channel capacities are averaged over 100,000 Rayleigh fading realizations with the signal-to-noise ratio (SNR) of 14, 17, 20, 23, and $26 \mathrm{~dB}$ in the 8-antenna array. As seen in Figure 9b, with average increase of $3 \mathrm{~dB}$ in SNR, the channel capacity changes drastically in both bands. In lower band, the channel capacity from 14 to $26 \mathrm{SNR}$ ranges from $24.6 \mathrm{bps} / \mathrm{Hz}$ to $52 \mathrm{bps} / \mathrm{Hz}$. In higher band it varies in between $25.9 \mathrm{bps} / \mathrm{Hz}$ to $60 \mathrm{bps} / \mathrm{Hz}$. In SNR value of $20 \mathrm{~dB}$, the peak value of $38.9 \mathrm{in}$ lower band and $39.5 \mathrm{bps} / \mathrm{Hz}$ in higher resonating band is seen. Hence, delivering the desired performance in both resonating bands.

Diversity gain refers to improvements in signal-to-interference ratio by applying any diversity scheme. As the antenna shows diversity gain with higher values, this means a better isolation is achieved. In Figure 9c the diversity of the proposed MIMO antenna over the entire operational bandwidth can be seen higher. The MEG of the antenna show how well antenna performed in a real multipath propagating environment. Table 1 shows the calculated value of MEGs using equation mentioned in [13] and is found to be less than 1.

\subsection{SAR Analysis}

In order to implement safety standards for user mobile terminals, the SAR of proposed MIMO antenna is implemented. SAR intensity must be checked for safety purposes which must not exceed the range value of $1.6 \mathrm{~W} / \mathrm{Kg}$ for $1-\mathrm{g}$ tissue and $2 \mathrm{~W} / \mathrm{Kg}$ for $10 \mathrm{-g}$ tissue [30-33]. The SAR Analysis was carried out in ANSYSS HFSS simulator 2013 version. Since the proposed model is designed for smartphone applications, therefore, the antennas were placed near the head (talking mode). Having an input power of $25 \mathrm{~mW}$ supplied to antenna elements, the SAR analysis was performed. Figure 10 shows the SAR results of the proposed MIMO antenna system for $1-\mathrm{g}$ tissue. The peak SAR value of $1.40 \mathrm{~W} / \mathrm{Kg}$ was observed hence laying in safety limits for usage. 


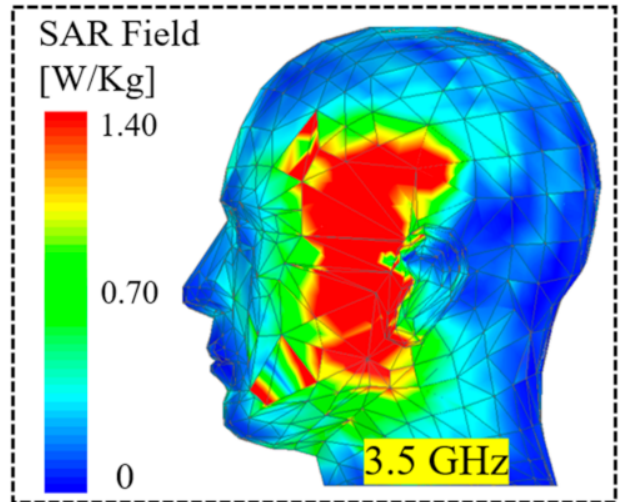

(a)

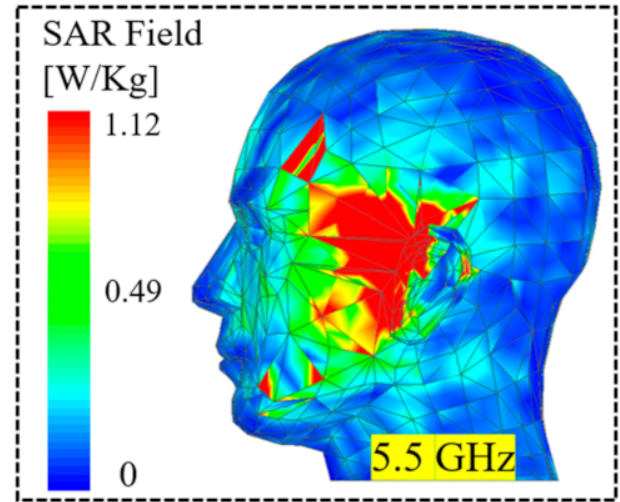

(b)

Figure 10. SAR Analysis of proposed dual band Antenna. (a) $3.5 \mathrm{GHz}$ (b) $5.5 \mathrm{GHz}$.

The comparison is given in Table 2. Comparison table is included in order to indicate clear contribution of proposed MIMO system. The proposed antenna can be seen as well designed as compared to published literature since most of the literature is found to be on single band coverage. The ECC and gain values are good and measured isolation value of $14 \mathrm{~dB}$ is recorded. Furthermore, the proposed antenna system exhibits good channel capacity of $39.5 \mathrm{bps} / \mathrm{Hz}$ approximately 2.89 times that of $2 \times 2$ port MIMO system.

Table 2. Comparison Table of proposed MIMO system.

\begin{tabular}{cccccccc}
\hline Reference & Frequency (GHz) & Board Size & $\begin{array}{c}\text { Antenna } \\
\text { Element }(\mathbf{L} \\
\times \mathbf{W})\end{array}$ & $\begin{array}{c}\text { Isolation } \\
\mathbf{( d B )}\end{array}$ & $\begin{array}{c}\text { Efficiency } \\
\mathbf{( \% )}\end{array}$ & ECC & CC \\
\hline$[4]$ & $3.4-3.6$ & $136 \times 68$ & $3 \times 9$ & 11 & $60-70$ & $<0.1$ & 32 \\
{$[5]$} & $3.3-3.7$ & $150 \times 75$ & $5.6 \times 4.6$ & 15 & $52-68$ & $<0.1$ & 38 \\
{$[9]$} & $3.4-3.6 / 5.4-5.6$ & $140 \times 70$ & $9.6 \times 10$ & 11 & $51-59 / 62-80$ & $<0.1$ & 36 \\
{$[10]$} & $3.4-3.6 / 5.1-5.9$ & $150 \times 75$ & $14.9 \times 4$ & 12 & $60-65 / 58-70$ & $<0.2$ & 40 \\
{$[12]$} & $2.6-3.6$ & $150 \times 75$ & $7 \times 6$ & 15 & $52-72$ & $<0.2$ & 35 \\
{$[13]$} & $2.4-2.7 / 3.4-3.6$ & $124 \times 74$ & $6.8 \times 6$ & 14 & $40-58 / 60-70$ & $<0.1$ & $\mathrm{~N} / \mathrm{A}$ \\
{$[14]$} & $1.8-1.92 / 2.3-2.4$ & $136 \times 68$ & $14 \times 16$ & $\mathrm{~N} / \mathrm{A}$ & $40-58 / 52-70$ & $<0.15$ & $\mathrm{~N} / \mathrm{A}$ \\
{$[34]$} & $3.4-3.6$ & $150 \times 75$ & $12.5 \times 18.5$ & 12 & $42-65$ & $<0.2$ & 38.5 \\
{$[35]$} & $3.4-3.6$ & $150 \times 75$ & $14.3 \times 5.8$ & 14 & $45-70$ & $>0.2$ & 38.5 \\
Proposed & $3.4-3.6 / 5.4-5.6$ & $150 \times 75$ & $2.5 \times 11.5$ & 14 & $63-69 / 52-58$ & $<0.1$ & 39.5 \\
\hline
\end{tabular}

\section{Conclusions}

This paper presents a dual band eight port MIMO antenna system covering two distinct bands of LTE band 42 and LTE Band 46 for future 5G smartphones. The performance parameters such as efficiency, gain and other MIMO performance parameters were discussed and the optimization of the proposed antenna was elaborated. The antenna exhibits good performance with pattern and spatial diversity characteristics and the efficiency of the system was found from $52 \%$ to $69 \%$ throughout the operational bandwidth. A fabricated prototype was developed and the measured results well agree with simulated ones. In future, the proposed system can further be enhanced for tri and quad band response so that the antennas can resonate at $5 \mathrm{G}$ as well as $4 \mathrm{G}$ band systems. Through its robust characteristics, and reliable performance, the proposed antenna can be considered as a potential candidate for future 5G smart phones and other wireless terminals applications for high data rate delivery.

Author Contributions: Conceptualization, H.A. and I.B.; methodology, H.A. and I.B.; software, H.A. and I.B.; validation, S.I.M., M.R.A. and I.B.; formal analysis, S.I.M. and N.J.; investigation, X.-C.R. and W.U.K.T.; resources, X.-C.R. and A.M.H.; data curation, S.I.M. and W.U.K.T.; writing-original draft 
preparation, A.I. and M.A.K.; writing—review and editing, A.I. and M.A.K.; visualization, M.R.A.; supervision, X.-C.R. and A.M.H.; project administration, H.A. and N.J.; funding acquisition, X.-C.R. and M.R.A. All authors have read and agreed to the published version of the manuscript.

Funding: This project is supported by National Natural Science Foundation of China (61861043).

Data Availability Statement: All the data has been included in the study.

Conflicts of Interest: The authors declare no conflict of interest.

\section{References}

1. Anitha, R.; Vinesh, P.V.; Prakash, K.C.; Mohanan, P.; Vasudevan, K. A Compact Quad Element Slotted Ground Wideband Antenna for MIMO Applications. IEEE Trans. Antennas Propag. 2016, 64, 4550-4553. [CrossRef]

2. Abd-Alhameed, R.A.; Elfergani, I.; Rodriguez, J. Recent Technical Developments in Energy-Efficient 5G Mobile Cells: Present and Future. Electronics 2020, 9, 664. [CrossRef]

3. Zhao, A.; Ren, Z. Wideband MIMO antenna systems based on coupled-loop antenna for 5G N77/N78/N79 applications in mobile terminals. IEEE Access 2019, 7, 93761-93771. [CrossRef]

4. Abdullah, M.; Kiani, S.H.; Abdulrazak, L.F.; Iqbal, A.; Bashir, M.A.; Khan, S.; Kim, S. High-Performance Multiple-Input Multiple-Output Antenna System For 5G Mobile Terminals. Electronics 2019, 8, 1090. [CrossRef]

5. Abdullah, M.; Altaf, A.; Anjum, M.R.; Arain, Z.A.; Jamali, A.A.; Alibakhshikenari, M.; Falcone, F.; Limiti, E. Future Smartphone: MIMO Antenna System for 5G Mobile Terminals. IEEE Access 2021, 9, 91593-91603. [CrossRef]

6. Li, Z.; Du, Z.; Takahashi, M.; Saito, K.; Ito, K. Reducing Mutual Coupling of MIMO Antennas With Parasitic Elements for Mobile Terminals. IEEE Trans. Antennas Propag. 2012, 60, 473-481. [CrossRef]

7. Li, H.; Miers, Z.T.; Lau, B.K. Design of Orthogonal MIMO Handset Antennas Based on Characteristic Mode Manipulation at Frequency Bands Below 1 GHz. IEEE Trans. Antennas Propag. 2014, 62, 2756-2766. [CrossRef]

8. Jaglan, N.; Gupta, S.D.; Sharawi, M.S. 18 Element Massive MIMO/Diversity 5G Smartphones Antenna Design for Sub-6 GHz LTE Bands $42 / 43$ Applications. IEEE Open Access J. Antenna Propag. 2021, 2, 533-545. [CrossRef]

9. Li, J.; Zhang, X.; Wang, Z.; Chen, X.; Chen, J.; Li, Y.; Zhang, A. Dual-Band Eight-Antenna Array Design for MIMO Applications in 5G Mobile Terminals. IEEE Access 2019, 7, 71636-71644. [CrossRef]

10. Zou, H.; Li, Y.X.; Sim, C.-Y.-D.; Yang, G.L. Design of $8 \times 8$ dual-band MIMO antenna array for 5G smartphone applications. Int. J. RF Microwave Comp. Aided Eng. 2018, 28, 1-12.

11. Li, Y.X.; Sim, C.-Y.-D.; Luo, Y.; Yang, G.L. 12-port 5G massive MIMO antenna array in sub-6GHz mobile handset for LTE bands 42/43/46 applications. IEEE Access 2018, 6, 344-354. [CrossRef]

12. Abdullah, M.; Kiani, S.H.; Iqbal, A. Eight Element Multiple-Input Multiple-Output (MIMO) Antenna for 5G Mobile Applications. IEEE Access 2019, 7, 134488-134495. [CrossRef]

13. Jiang, W.; Cui, Y.; Liu, B.; Hu, W.; Xi, Y. A Dual-Band MIMO Antenna With Enhanced Isolation for 5G Smartphone Applications. IEEE Access 2019, 7, 112554-112563. [CrossRef]

14. Geyi, Z.Q.W.; Zhang, M.; Wang, J. Printed eight-element MIMO system for compact and thin 5G mobile handset. Electron. Lett. 2016, 52, 416-418.

15. Saraereh, O.A. A Novel Broadband Antenna Design for 5G Applications. Comput. Mater. Contin. 2021, 67, 1121-1136. [CrossRef]

16. Sreelakshmy, R.; Vairavel, G. Novel cuff button antenna for dual-band applications. ICT Express 2019, 5, 26-30. [CrossRef]

17. Raad, H.R.; Abbosh, A.I.; Al-Rizzo, H.M.; Rucker, D.G. Flexible and Compact AMC Based Antenna for Telemedicine Applications. IEEE Trans. Antennas Propag. 2013, 61, 524-531. [CrossRef]

18. Iqbal, A.; Selmi, M.A.; Abdulrazak, L.F.; Saraereh, O.A.; Mallat, N.K.; Smida, A. A Compact Substrate Integrated Waveguide Cavity-Backed Self-Triplexing Antenna. IEEE Trans. Circuits Syst. II Express Briefs 2020, 67, 2362-2366. [CrossRef]

19. Mohamadzade, B.; Simorangkir, R.B.V.B.; Hashmi, R.M.; Gharaei, R.; Lalbakhsh, A.; Shrestha, S.; Zhadobov, M.; Sauleau, R. A Conformal, Dynamic Pattern-Reconfigurable Antenna Using Conductive Textile-Polymer Composite. IEEE Trans. Antennas Propag. 2021, 69, 6175-6184. [CrossRef]

20. Lalbakhsh, A.; Afzal, M.U.; Esselle, K.P.; Smith, S. Wideband Near-Field Correction of a Fabry-Perot Resonator Antenna. IEEE Trans. Antennas Propag. 2019, 67, 1975-1980. [CrossRef]

21. Mohamadzade, B.; Simorangkir, R.B.V.B.; Hashmi, R.M.; Lalbakhsh, A. A Conformal Ultrawideband Antenna With MonopoleLike Radiation Patterns. IEEE Trans. Antennas Propag. 2020, 68, 6383-6388. [CrossRef]

22. Mohamadzade, B.; Hashmi, R.M.; Simorangkir, R.B.V.B.; Lalbakhsh, A.; Ali, H. A Planar Dynamic Pattern-Reconfigurable Antenna. In Proceedings of the IEEE 2021 15th European Conference on Antennas and Propagation (EuCAP), Dusseldorf, Germany, 22-26 March 2021; pp. 1-3.

23. Kamal, M.; Yang, S.; Kiani, S.; Anjum, M.; Alibakhshikenari, M.; Arain, Z.; Jamali, A.; Lalbakhsh, A.; Limiti, E. Donut-Shaped mmWave Printed Antenna Array for 5G Technology. Electronics 2021, 10, 1415. [CrossRef]

24. Sehrai, D.; Asif, M.; Shoaib, N.; Ibrar, M.; Jan, S.; Alibakhshikenari, M.; Lalbakhsh, A.; Limiti, E. Compact Quad-Element High-Isolation Wideband MIMO Antenna for mm-Wave Applications. Electronics 2021, 10, 1300. [CrossRef] 
25. Elfergani, I.; Rodriguez, J.; Iqbal, A.; Sajedin, M.; Zebiri, C.; A AbdAlhameed, R. Compact Millimeter-Wave MIMO Antenna for 5G Applications. In Proceedings of the IEEE 2020 14th European Conference on Antennas and Propagation (EuCAP), Copenhagen, Denmark, 15-20 March 2020; pp. 1-5.

26. Iqbal, A.; Altaf, A.; Abdullah, M.; Alibakhshikenari, M.; Limiti, E.; Kim, S. Modified U-Shaped Resonator as Decoupling Structure in MIMO Antenna. Electronics 2020, 9, 1321. [CrossRef]

27. Altaf, A.; Iqbal, A.; Smida, A.; Smida, J.; Althuwayb, A.A.; Hassank Kiani, S.; Alibakhshikenari, M.; Falcone, F.; Limiti, E. Isolation Improvement in UWB-MIMO Antenna System Using Slotted Stub. Electronics 2020, 9, 1582. [CrossRef]

28. Elfergani, I.; Iqbal, A.; Zebiri, C.; Basir, A.; Rodriguez, J.; Sajedin, M.; Pereira, A.D.O.; Mshwat, W.; Abd-Alhameed, R.; Ullah, S. Low-Profile and Closely Spaced Four-Element MIMO Antenna for Wireless Body Area Networks. Electronics 2020, 9, 258. [CrossRef]

29. Mohamadzade, B.; Simorangkir, R.B.V.B.; Maric, S.; Lalbakhsh, A.; Esselle, K.P.; Hashmi, R. Recent Developments and State of the Art in Flexible and Conformal Reconfigurable Antennas. Electronics 2020, 9, 1375. [CrossRef]

30. Iqbal, A.; Saraereh, O.A.; Ahmad, A.W.; Bashir, S. Mutual Coupling Reduction Using F-Shaped Stubs in UWB-MIMO Antenna. IEEE Access 2018, 6, 2755-2759. [CrossRef]

31. Iqbal, A.; A Saraereh, O.; Bouazizi, A.; Basir, A. Metamaterial-Based Highly Isolated MIMO Antenna for Portable Wireless Applications. Electronics 2018, 7, 267. [CrossRef]

32. Iqbal, A.; Basir, A.; Smida, A.; Mallat, N.K.; Elfergani, I.; Rodriguez, J.; Kim, S. Electromagnetic Bandgap Backed Millimeter-Wave MIMO Antenna for Wearable Applications. IEEE Access 2019, 7, 111135-111144. [CrossRef]

33. Iqbal, A.; Smida, A.; Alazemi, A.J.; Waly, M.I.; Mallat, N.K.; Kim, S. Wideband Circularly Polarized MIMO Antenna for High Data Wearable Biotelemetric Devices. IEEE Access 2020, 8, 17935-17944. [CrossRef]

34. Kiani, S.H.; Altaf, A.; Anjum, M.R.; Afridi, S.; Arain, Z.A.; Anwar, S.; Khan, S.; Alibakhshikenari, M.; Lalbakhsh, A.; Khan, M.A.; et al. MIMO Antenna System for Modern 5G Handheld Devices with Healthcare and High Rate Delivery. Sensors 2021, $21,7415$. [CrossRef] [PubMed]

35. Kiani, S.H.; Altaf, A.; Abdullah, M.; Muhammad, F.; Shoaib, N.; Anjum, M.R.; Damaševičius, R.; Blažauskas, T. Eight Element Side Edged Framed MIMO Antenna Array for Future 5G Smart Phones. Micromachines 2020, 11, 956. [CrossRef] [PubMed] 